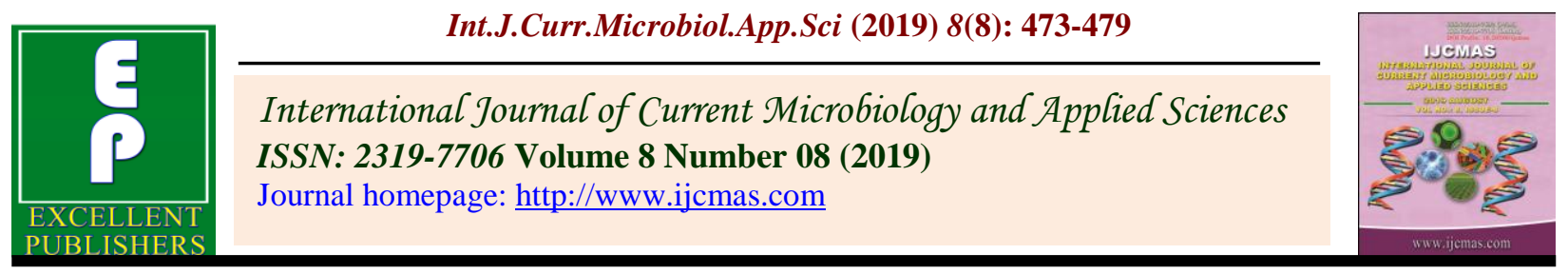

Review Article

https://doi.org/10.20546/ijcmas.2019.808.054

\title{
Morphogenesis of Mammary Gland in Indian Buffalo (Bubalus bubalis): A Review on Prenatal Study
}

\author{
Challana Amit*, Anuradha Gupta, Neelam Bansal and Varinder Uppal \\ Department of Veterinary Anatomy, College of Veterinary Sciences, Guru Angad Dev \\ Veterinary and Animal Sciences University, Ludhiana, Punjab, India \\ *Corresponding author
}

\begin{tabular}{|l|}
\hline Ke y w o r d s \\
Buffalo, Mammary \\
gland, Mammary \\
bud, Primary \\
Sprout, Fat pad, \\
Gland sinus
\end{tabular}

A B S T R A C T

The mammary gland develops through several distinct stages. The first transpires in the embryo as the ectoderm forms a mammary line that resolves into placodes which leads to various stages like mammary bud, primary sprout, secondary and tertiary sprouts. Simultaneously the connective tissue whorls, fat pad, teat and gland sinus and other associated structures like sweat and sebaceous glands are also developed. Regulated by epithelial/mesenchymal interactions, the placodes descend into the underlying mesenchyme and produce the ductal structure of the gland present at birth. These processes require numerous signaling pathways that fuel the dramatic changes in the gland occurring during prenatal life. Our knowledge of morphogenesis of mammary gland and its biology may reveal the ways to manipulate the development of mammary gland to enhance milk production in mature buffalo and to treat various diseases.

\section{Introduction}

Buffalo breed needs a systematic genetic improvement programme and efficient measures for their conservation (Singh, 2006). This breed plays a significant role in rural livelihood of India in terms of draught, milk and manure. The name "Black Gold" has emerged as synonym for the one very popular breed of buffaloes i.e. Murrah, which serves as capital reserve or cash crops to rural folk by producing economic stability, livelihood security and social status. The mammary gland distinguishes mammals from all other animals with its unique anatomical structure that secretes milk for the nourishment of the newborn (Jenkinson, 2003). They are complex secretory organs composed of a number of different cell types: epithelial cells that grow from the teat into a fat pad, formed by adipocytes and infiltrated by vascular endothelial cells, fibroblasts and immune cells (Akers, 2002). This article focuses primarily on the epithelial changes during prenetal life of Indian buffalo (Bubalus bubalis). Here, we review how basic morphogenesis shape the 
structure of the gland at each stage of development.

\section{Morphogenesis of mammary gland}

\section{Mammary line}

Anderson (1978) reported that mammary band developed at $9 \mathrm{~mm}$ CRL in sheep, $5 \mathrm{~mm}$ CRL in goat and $14 \mathrm{~mm}$ CRL in cattle. Similarly, Carroll (1980) and Ellis (1998) observed that the mammary gland formed from an invagination of ectoderm at $1.4 \mathrm{~cm}$ CVRL in cow embryo. Challana et al., (2014) reported that the earliest recognizable stage of mammary gland development in the present study was mammary line found in $1.2 \mathrm{~cm}$ CVRL (34 days) buffalo foetus on the ventral side in the inguinal region posterior to umbilicus. Whereas, Akers (2002) described that the mammary band was formed at $30^{\text {th }}$ day in bovine foetuses. However, Jenkinson (2003) reported that the mammary band run along both sides of the midline in the inguinal region at day 40 in sheep foetuses.

Anderson (1978) found mammary line at 10 $\mathrm{mm}$ CRL in sheep, $10 \mathrm{~mm}$ CRL in goat and $17 \mathrm{~mm}$ CRL in cattle and mammary crest was observed at $15 \mathrm{~mm}$ CRL in sheep, $28 \mathrm{~mm}$ CRL in goat and $19 \mathrm{~mm}$ CRL in cattle. Panchal et al., (1998a) reported that a pair of mammary line appeared in the inguinal region on either side of mid ventral line, medial to thigh at 38 days $(1.0 \mathrm{~cm}$ CRL) in buffalo foetuses. Whereas, Singh (2000) observed four mammary anlages on the ventral abdominal wall caudal to umbilicus between the hind limbs in buffalo foetus at 90-109 days of gestation.

Challana et al., (2014) reported that the proliferation of mesenchymal cells resulted in condensation of mammary line into mammary hillock at $1.7 \mathrm{~cm}$ CVRL (37 days) of fetal age. The mammary hillock was cone shaped.
Akers (2002) reported that mammary streak became the mammary line by fifth week of development in bovine foetuses. Jenkinson (2003) noticed the mammary line in the inguinal area posterior to umbilicus at 40 days in sheep foetuses. Whereas, McGeady et al., (2006) stated that the mammary line extended from the forelimb buds to the hind limb buds at 30 days of gestation in bovine foetus. However, Vaish (2012) reported that the initiation of the development of the mammary gland was observed as mammary line in the inguinal region on either side of the median line, medial to thigh in $4.50 \mathrm{~cm}$ CRL and discoid shaped mammary crest in $5.00 \mathrm{~cm}$ CRL goat foetuses.

\section{Mammary bud}

Anderson (1978) described mammary hillock at $20 \mathrm{~mm}$ CRL in sheep, $29 \mathrm{~mm}$ CRL in goat and $21 \mathrm{~mm}$ CRL in cattle. Whereas, mammary bud was observed at $25 \mathrm{~mm}$ CRL in sheep, $30 \mathrm{~mm}$ CRL in goat and $25 \mathrm{~mm}$ CRL in cattle. Carroll (1980) reported mammary bud at $3.0 \mathrm{~cm}$ CRL in cow foetuses. Turner and Huynh (1991) reported that mammary bud was most often elongated and ovoid in shape and was carried outward with the developing teat rather than beginning to invade the underlying mesenchymal tissue in cattle embryo. Challana et al., (2014) reported that the mammary bud is the prominent stage of mammary embryonic development in buffaloes. It was observed in $2.6 \mathrm{~cm}$ CVRL (41 days) buffalo foetus. The later was ovoid in shape with its long axis perpendicular to the surface of the foetus.

Ellis (1998) observed that the mammary hillock and bud were the prominent stages of mammary embryonic development in ruminants. Panchal et al., (1998a) in buffalo foetuses and Akers (2002) in bovine foetuses noticed the mammary bud at 55 days $(4.20 \mathrm{~cm}$ CVRL) and 43 days, respectively and 
Jenkinson (2003) found mammary bud at 40 days in sheep foetuses. McGeady et al., (2006) described that mammary crest developed into mammary bud at 30 days of gestation in bovine foetus. However, Hyttel et al., (2010) stated that the mammary bud lengthened and branched from day 58 onwards in bovines.

Chaurasia et al., (2012) observed formation of mammary bud between 4.4 to $6.0 \mathrm{~cm}$ CRL (44-49 days) and the cells of the mammary bud progressed deeper into the dermis at 7.9 $\mathrm{cm}$ CRL in goat foetus. Similarly, Vaish (2012) observed that the stratum germinativum in the area of mammary hillock rounded off and submerged in the underlying tissue due to continuous proliferation of the new cells to form the complete mammary bud in $6.70 \mathrm{~cm}$ CRL goat foetus.

\section{Primary sprout}

Anderson (1978) described primary sprout at 56 days of gestation in sheep, 50 days in goat and 80 days in cattle. Similarly, Carroll (1980) found the primary sprout at $12.0 \mathrm{~cm}$ CRL in cow foetuses.

Panchal et al., (1998a) reported that primary sprout got elongated and entered deep into the teat base at 102 days $(14.30 \mathrm{~cm}$ CRL). At 108 days (16.0 cm CRL), the luminization of the primary sprout was found in its proximal rounded end. The luminization progressed towards the distal end of the duct near the teat apex in 120 days $(18.50 \mathrm{~cm}$ CRL) buffalo foetuses. Similarly, Singh (2000) found that the canalization of primary sprout started in the centre at the proximal end and preceded to distal end at 120 to 146 days in buffalo foetuses.

Akers (2002) described the primary sprout at day 80 in bovine. Jenkinson (2003) noticed primary sprout at $15.0 \mathrm{~cm}$ CRL (60 days) in sheep foetus. The later was canalized and extended up to full length of the duct. Chaurasia et al., (2012) observed that the primary sprout sunk deeper into the teat base at $12.5 \mathrm{~cm}$ CRL (64 days) in goat foetuses. Later on luminization of the primary sprout took place at $12.8 \mathrm{~cm}$ CRL and showed that luminized primary sprout continued its development deep into the future glandular part of the udder. Similarly, Vaish (2012) reported the primary sprout at $11.50 \mathrm{~cm}$ CRL in goat foetuses. This structure got extended as a cellular cord and entered deep into the base of the teat at $12.50 \mathrm{~cm}$ CRL. The luminization of the primary sprout from the base towards the apex of the teat was observed in $17.60 \mathrm{~cm}$ CRL and $12.8 \mathrm{~cm} \mathrm{CRL}$ in goat foetuses by (Vaish, 2012) and (Chaurasia et al., 2012), respectively. Whereas Challana et al., 2014 revealed that the mesenchymal cells surrounding the mammary bud proliferated to form the outward projection of mammary tissue which developed to epidermal cone (primitive teat) at $6.7 \mathrm{~cm}$ CVRL (58 days) in the inguinal region of buffalo foetus. The epidermal cells of the bud elongated by rapid cell prolife ration into the underlying mesenchymal tissue along the length of the teat to form primary sprout at $7.4 \mathrm{~cm}$ CVRL (62 days) of fetal age. These cells got extended as cellular chords and enter deep into the base of teat at $10.7 \mathrm{~cm}$ CVRL (77 days). The primary sprout gave rise to the teat cistern, gland cistern and major duct system of mammary gland.

\section{Secondary sprout}

Anderson (1978) found secondary sprouts at 59 days in sheep, 60 days in goat and 90 days in cattle foetuses. Forsyth et al., (1999) and Jenkinson (2003) noticed numerous secondary sprouts at 80 days of sheep foetuses. Singh (2000) reported secondary sprout at 254 days in buffalo foetuses. However, Akers (2002) described the 
secondary sprout at 90 days in bovine foetuses.

McGeady et al., (2006) stated that eight to twelve secondary sprouts radiate from the gland sinus into the surrounding tissue after the fourth month in bovine foetuses. Whereas Chaurasia et al., (2012) reported secondary sprouts at $13.8 \mathrm{~cm}$ CRL (68 days) in goat foetuses. Challana et al., 2014 found that the secondary sprouts were budding off at different angles to the proximal end of the primary sprout in various directions between 14-17 cm CRL (69- 78 days) in goat foetuses. These ducts were anlagen of the duct system of the udder. The secondary sprouts appeared as irregular shaped hollow sacks at $15 \mathrm{~cm}$ CVRL (96 days) of fetal age. These ducts would form the duct system of the mammary gland. The lumen of secondary sprouts began to grow by cellular degeneration of epithelial cells of primary sprout at various angles into the surrounding mesenchyme at $18.2 \mathrm{~cm}$ CVRL (110 days) as the rapidly growing epithelial cells were unable to obtain nutrients. The secondary sprouts gave rise to tertiary branches at 21.2 cm CVRL (122 days) and further branching of the tertiary ducts was observed at $24.1 \mathrm{~cm}$ CVRL (130 days) that proceeded towards the fat pad.

\section{Teat formation}

Anderson (1978) described development of teat at $6.0 \mathrm{~cm}$ CRL (46 days) in sheep and 8.0 cm CRL (65 days) in cattle foetuses. Sheffield (1988) reported development of teat at 80 day of gestation in bovine foetuses. Panchal et al., (1998a) found that the development of teat was initiated by an elevation of epidermal cone surrounding the mammary bud at 5.70 $\mathrm{cm}$ CRL in buffalo foetuses whereas, Akers (2002) stated that the teat development by day 65 in bovine foetuses. Chaurasia et al., (2012) and Vaish (2012) observed a papilla like teat discernible on either side of midline in inguinal region between two thighs at $9.5 \mathrm{~cm}$ CRL (58 days) and $6.70 \mathrm{~cm}$ CRL, respectively in goat foetuses. Challana et al., (2014) found that as the age advanced, gradually the epidermal cone got elevated along the mammary bud and the development of teat was initiated at $6.7 \mathrm{~cm}$ CVRL (58 days). With increasing age, the length of teat also increased.

\section{Fat pad}

Sheffield (1988) and Panchal et al., (1999a) reported formation of fat pad at 80 and 189 days in cattle and buffalo foetuses, respectively. Whereas Forsyth et al., (1999) and Jenkinson (2003) found fat pad at day 140 and day 80 respectively, in sheep foetuses.

Singh (2000) found fat pad at 120 days of fetal life in buffalo. Whereas, McGeady et al., (2006) described formation of mammary fat pad on the base of the developing mammary gland at 180 day of gestation in cattle. Chaurasia et al., (2012) and Vaish (2012) reported that the fat pad developed by branching of the secondary sprouts and differentiation of spherical masses of mesenchymal tissue at $19.5 \mathrm{~cm}$ and $20.0 \mathrm{~cm}$ CRL, respectively in goat foetuses. Challana et al., (2014) found that the mesenchymal cells at the base of developing mammary gland differentiated into fat pad at $45.5 \mathrm{~cm}$ CVRL (176 days) of buffalo foetus.

\section{Gland cistern}

Anderson (1978) described gland cistern at $23.0 \mathrm{~cm}$ CRL (130 days) in cattle foetus. Whereas, Carroll (1980) found gland cistern at 17.00 to $21.00 \mathrm{~cm}$ CRL in cow foetus. Jenkinson (2003) found the gland cistern near the proximal end of primary sprout at day 80 in sheep foetuses. Chaurasia et al., (2012) 
noticed highly proliferative growth of gland cistern and all the ducts were luminized at $38.6 \mathrm{~cm}$ CRL (139 days). Whereas, Vaish (2012) observed gland cistern between the fat pad at $17.60 \mathrm{~cm}$ CRL goat foetuses. Challana et al., (2014) reported that the initiation of gland cistern was observed in $15 \mathrm{~cm}$ CVRL (96 days) buffalo foetus. The continual growth of the lumen of the primary sprout pushed back the cells lining the primary spout towards glandular tissue of developing mammary gland resulting in formation of fully developed gland cistern at $45.5 \mathrm{~cm}$ CVRL (176 days) in buffalo foetuses.

\section{Teat cistern}

Anderson (1978) observed the teat cistern at $30.0 \mathrm{~cm}$ CRL (110 days) in cattle. Whereas, Carroll (1980) found the teat cistern at 17.00 to $21.00 \mathrm{~cm}$ CRL in cow foetuses. The streak canal was the distal most part of the primary sprout that canalized at last but lumen was not fully formed up to 152-182 days in buffalo foetuses (Singh, 2000). Challana et al., (2014) found that the canalization of primary sprout proceeded downward and initiated the formation of teat cistern in $15 \mathrm{~cm}$ CVRL (96 days) of buffalo foetus. Well distinct teat cistern was noticed at $24.1 \mathrm{~cm}$ CVRL (130 days).The lumen of teat cistern continued downward to form teat canal at $21.2 \mathrm{~cm}$ CVRL (122 days) of buffalo foetus.

Akers (2002) described the streak canal and teat cistern at 100 days in bovine foetuses. Jenkinson (2003) reported the teat cistern at 80 days in sheep foetuses. At day 140 of fetal age the entire gland greatly increased in size due to lengthening of the primary sprout which developed to teat and gland cisterns.

McGeady et al., (2006) and Hyttel et al., (2010) described teat cistern at 120 days of gestation in mammals. Chaurasia et al., (2012) noticed the teat canal at $21.7 \mathrm{~cm} \mathrm{CRL}$
(91 days) in goat foetuses. The lumen of teat cistern became wide and increased height of the primary and secondary mucosal folds were also noticed at this age. However, Vaish (2012) reported teat cistern in $34.00 \mathrm{~cm}$ CRL in goat fetuses and Challana et al., (2014) found that the rosette of furstenberg was observed at $39.5 \mathrm{~cm}$ CVRL (163 days) at junction of teat canal and streak canal and keratin plug was found at $45.5 \mathrm{~cm}$ CVRL (176 days) of buffalo fetuses

\section{Micro vascularization}

Carroll (1980) observed that blood vessels were formed in the mesenchyme surrounding the primary sprout at 17.00 to $19.00 \mathrm{~cm}$ of cow foetuses. Akers (2002) stated that the blood vessels began to form at day 80 of gestation in bovines.

Jenkinson (2003) reported that Nerves and small blood vessels formed in close association with each bundle of developing adipose tissue at day 80 and elastic fibres at day 90 in sheep foetuses. Chaurasia et al., (2012) and Vaish (2012) reported that the numerous blood capillaries invaded the bud at $4.4 \mathrm{~cm}$ to $6.0 \mathrm{~cm}$ CRL (44 -49 days) and 7.20 $\mathrm{cm}$ CRL in goat foetuses, respectively.

The small blood vessels were observed in the mesenchymal tissue of mammary bud at 2.6 cm CVRL (41 days) of buffalo foetus.

At $18.2 \mathrm{~cm}$ CVRL (110 days), nerves and small blood vessels were found in close association with connective tissue whorl. With advancement of fetal age, the numerous blood vessels were seen around secondary sprout and developing gland and teat cistern. At $69 \mathrm{~cm}$ CVRL (229 days), blood and lymphatic vessels along with nerve bundles were present throughout the mammary gland (Challana et al., 2014). 


\section{Skin and its appendages}

Bhayani et al., (1992) observed a distinct epidermis and dermis between 74-115 days of gestation in buffalo. Panchal et al., (1999b) observed increased in cell layer of epidermis for 3-4 at 73 days of gestation to 12-15 at 191 days of buffalo foetus. Singh (2006) revealed that the skin was comprised of distinct epidermis and dermis at $5.5 \mathrm{~cm}$ CVRL (53 days) in bovine foetus.

Malik et al., (1996) reported that the epithelium was divided into 4 layers on stratum germinativum, stratum granulosum, stratuminter medium and stratum basale in goat foetus. Challana et al., (2014) found that the skin was comprised of distinct epidermis and dermis at $6.7 \mathrm{~cm}$ CVRL (58 days) buffalo foetuses. Epidermis was 4-5 cell layers thick at $6.7 \mathrm{~cm}$ CVRL (58 days) which was increased to 7-8 cell layers at $7.4 \mathrm{~cm}$ CVRL (62 days) and $12-14$ at $10.7 \mathrm{~cm}$ CVRL (77days). With advancing fetal age, thickness of epidermis decreased and became 4-5 cell layers at $18.2 \mathrm{~cm}$ CVRL (110 days).Dermis was clearly divided in two layers at $18.2 \mathrm{~cm}$ CVRL (110 days). Outer layer i.e. towards epidermis was loosely arranged whereas the inner layer was dense. The thickness of dermis increased with advancement of fetal age.

Carroll (1980) observed hair follicles began at 120 days of cow foetus. Bhayani et al., (1992) and Panchal et al., (1999b) reported first evidence of hair follicle at 115-120 days and 102 days respectively in buffalo foetuses. McGeady et al., (2006) described that the hair follicles began to develop around the $120^{\text {th }}$ day of gestation in bovines. Challana et al., (2014) Jenkinson (2003) observed the presence of hair follicles along the entire length of the teat at 80 days of gestation in sheep foetuses. Chaurasia et al., (2009) reported the hair follicle on the teat at 65 days in goat foetuses. Challana et al., (2014) observed that the primordia of hair follicle at $6.7 \mathrm{~cm}$ CVRL (58 days) buffalo foetus.

Bhayani et al., (1992) observed the sweat gland at 140-150 days buffalo foetuses. Panchal et al., (1999b) reported that the primordium of sweat glands at 139 day in buffalo foetus. Chaurasia et al., (2009) observed the sweat glands for the first time at 83 days in goat foetuses.

Panchal et al., (1999b) reported the sebaceous gland at 158 days in buffalo foetuses. Whereas Jenkinson (2003) reported sebaceous glands associated with each primary follicle at 120 days in sheep foetuses. Chaurasia et al., (2009) reported bunch of sebaceous gland around the hair follicles in 117-139 days goat foetuses. Challana et al., (2014) found that the primordia of sweat and sebaceous glands were found at $21.2 \mathrm{~cm}$ CVRL (122 days) of buffalo foetus.

\section{References}

Akers, R. M. "Overview of mammary development," in Lactation and the Mammary Gland, R. M. Akers, Ed., pp. 344, Lowa State Press, Ames, Iowa, USA, 2002.

Anderson, R. R., "Embryonic and foetal development of the mammary apparatus," in Lactation. A Comprehensive Treatise, B. L. Larson, Ed., pp. 3-40, Academic Press, New York, NY, USA, 1978.

Bhayani, D. M., K. M. Panchal, K. N. Vyas, and G. Baishya, "Histomorphological study on prenatal development of skin in surtibuffaloes," The Indian Journal of Animal Sciences, vol. 62, pp. 421-423, 1992.

Carroll, E. J. "Lactation," in Veterinary Endocrinology and Reproduction, L. E. McDonald, Ed., pp. 513-528, Elia and Febiger, Philadelphia, Pa, USA, 3rd edition, 1980.

Challana, A., A. Gupta, N. Bansal, and V. Uppal, "Morphogenesis of Mammary Glands in 
Buffalo (Bubalusbubalis)," Anatomy Research International, vol. 2014, Article ID 687936, 8 pages, 2014. https://doi.org/10.1155/2014/687936.

Chaurasia, S., K. M. Panchal, Y. L. Vyas, and M. C. Desai, "Histomorphological study on skin and its Adnexa on the Mammary Glands of Prenatal Non-descript goat," Indian Journal of Veterinary Anatomy, vol. 21, no. 1, pp. 40-42, 2009.

Chaurasia, S., K. M. Panchal, Y. L. Vyas, and M. C. Desai, "Organogenesis and Histogenes is of Mammary Gland in female goat (Capra hircus)," Indian Journal of Veterinary Anatomy, vol. 24, no. 2, pp. 67-70, 2012.

Eitedal, H., M. H. El-Sayed, E. O. H. El-Shafie, A. A. Saifelnasr, and E. E. Abu, "Histological and histochemical study on mammary gland of Damascus goat at milking stages," Egyptian Journal of Sheep and Goat Sciences, vol. 4, no. 1, pp. 75-88, 2009.

Ellis, S. E. Mechanisms controlling ductal morphogenesis in the ruminant mammary gland [Ph.D Dissertation], Virginia Polytechnic Institute and State University, Blacksburg, Va, USA, 1998.

Forsyth, I. A., G. Gabai, and G. Morgan, "Spatial and temporal expression of insulin-like growth factor-I, insulin-like growth factor-II and the insulin-like growth factor-I receptor in the sheep fetal mammary gland," Journal of Dairy Research, vol. 66, no. 1, pp. 35-44, 1999.

Hyttel, P., F. Sinowatz, and M. Vejlsted, Essentials of Domestic Animal Embryology, Elsevier Saunders, Philadelphia, Pa, USA, 2010.

Jenkinson, C. M. C. The pattern and regulation of mammary gland during foetal life in the sheep [Ph.D. Dissertation], Massey University, Palmerston North, New Zealand, 2003.
Malik, M. R. M. Tripathi, M. Srivastava A, and J. S. Taluja, "Histogenesis of epidermis in goats," in Proceedings of 11th Convention of IAVA, 1996.

McGeady, T. A., P. J. Quinn, E. S. F. Patrick, and M. T. Ryan, Veterinary Embryology, Blackwell Publishing, London, UK, 2006.

Panchal, K. M., K. N. Vyas, and Y. L. Vyas, "Histogenesis of skin and its adenexaof surtibuffalo," Indian Journal of Veterinary Anatomy, vol. 11, no. 2, pp. 158-160, 1999.

Panchal, K. M., K. N. Vyas, and Y. L. Vyas, "Organogenesis of the mammary gland in the female surti buffalo (Bubalus bubalis) I. Development from mammary line to sprout," Buffalo Journal, vol. 2, pp. 171-177, 1998.

Sheffield, L. G. "Organization and growth of mammary epithelia in the mammary gland fat pad," Journal of Dairy Science, vol. 71, no. 10, pp. 2855-2874, 1988.

Singh, N. Age correlated histomorphological and histochemical studies on the mammary gland of Indian buffalo (Bubalus bubalis) [M.S. thesis], Punjab Agricultural University, Ludhiana, Punjab, 2000.

Singh, R. Study on histogenesis of skin in Indian buffalo (Bubalusbubalis) [M.S. thesis], Guru Angad Dev Veterinary and Animal Sciences University, Ludhiana, Punjab, 2006.

Turner, J. D. and H. T. Huynh, "Role of tissue remodeling in mammary epithelial cell proliferation and morphogenesis," Journal of Dairy Science, vol. 74, no. 8, pp. 2801-2807, 1991.

Vaish, R. Histological, Histochemical and Ultrastructural Studies of Mammary Gland in Prenatal and Postnatal Non-Descript Goats, JNKVV Jabalpur, Madhya Pradesh, India, 2012.

\section{How to cite this article:}

Challana Amit, Anuradha Gupta, Neelam Bansal and Varinder Uppal. 2019. Morphogenesis of Mammary Gland in Indian Buffalo (Bubalus bubalis): A Review on Prenatal Study. Int.J.Curr.Microbiol.App.Sci. 8(08): 473-479. doi: https://doi.org/10.20546/ijcmas.2019.808.054 